\title{
Analysis in silico of the functional interaction between WNT5A and YAP/TEAD signaling in cancer
}

\author{
Pablo Astudillo ${ }^{\text {Corresp. } 1}$ \\ ${ }^{1}$ Instituto de Ciencias Biomédicas, Facultad de Ciencias de la Salud, Universidad Autónoma de Chile, Santiago, Chile \\ Corresponding Author: Pablo Astudillo \\ Email address: pablo.astudillo@uautonoma.cl
}

To date, most data regarding the crosstalk between the Wnt signaling pathway and the YAP/TAZ transcriptional coactivators focuses on the Wnt/ $\beta$-catenin branch of the pathway. In contrast, the relationship between the non-canonical Wnt pathway and YAP/TAZ remains significantly less explored. Wnt5a is usually regarded as a prototypical non-canonical Wnt ligand, and its expression has been related to cancer progression. On the other hand, YAP/TAZ transcriptional coactivators act in concert with TEAD transcription factors to control gene expression. Although one article has shown previously that WNT5A is a YAP/TEAD target gene, there is a need for further evidence supporting this regulatory relationship, because a possible YAP/Wnt5a regulatory circuit might have profound implications for cancer biology. This article analyzes publicly available ChIP-Seq, gene expression, and protein expression data to explore this relationship, and shows that WNT5A might be a YAP/TEAD target gene in several contexts. Moreover, Wnt5a and YAP expression are significantly correlated in specific cancer types, suggesting that the crosstalk between YAP/TAZ and the Wnt pathway is more intricate than previously thought. 


\section{Analysis in silico of the functional interaction between} 2 WNT5A and YAP/TEAD signaling in cancer

3

4

5

6

7

8

9

10

11

12

13

14

15

16

17

18

19

20

21

22

23

24

25

26

27

28

29

30

31

32

33

34

35

36

\section{Pablo Astudillo ${ }^{1}$}

${ }^{1}$ Instituto de Ciencias Biomédicas, Facultad de Ciencias de la Salud, Universidad Autónoma de Chile, Santiago, Chile

Corresponding Author:

Pablo Astudillo ${ }^{1}$

Email address: pablo.astudillo@uautonoma.cl

13

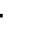

6

8

20

21

(3)

24

26

27

8

30


37

38

39

40

41

42

43

44

45

46

47

48

49

50

51

52

53

54

55

56

57

58

59

60

61

62

63

64

65

66

67

68

69

70

71

72

73

74

75

76

\section{Abstract}

To date, most data regarding the crosstalk between the Wnt signaling pathway and the YAP/TAZ transcriptional coactivators focuses on the Wnt/ $\beta$-catenin branch of the pathway. In contrast, the relationship between the non-canonical Wnt pathway and YAP/TAZ remains significantly less explored. Wnt5a is usually regarded as a prototypical non-canonical Wnt ligand, and its expression has been related to cancer progression. On the other hand, YAP/TAZ transcriptional coactivators act in concert with TEAD transcription factors to control gene expression. Although one article has shown previously that $W N T 5 A$ is a YAP/TEAD target gene, there is a need for further evidence supporting this regulatory relationship, because a possible YAP/Wnt5a regulatory circuit might have profound implications for cancer biology. This article analyzes publicly available ChIP-Seq, gene expression, and protein expression data to explore this relationship, and shows that WNT5A might be a YAP/TEAD target gene in several contexts. Moreover, Wnt5a and YAP expression are significantly correlated in specific cancer types, suggesting that the crosstalk between YAP/TAZ and the Wnt pathway is more intricate than previously thought.

\section{Introduction}

The Wnt signaling pathway modulates key processes during development and homeostasis, and alterations in this pathway have been related to disease (Logan \& Nusse, 2004). This pathway is commonly divided into two main branches. The Wnt/ $\beta$-catenin pathway, perhaps the best characterized, depends on the stabilization and nuclear translocation of $\beta$ catenin. Mechanistically, the activation of this pathway relies on the binding of Wnt ligands to Frizzled receptors and the co-receptors LRP5/6. The absence of Wnt stimulation leads to the degradation of $\beta$-catenin by a so-called $\beta$-catenin destruction complex, while activation of the pathway provokes the translocation of components of this destruction complex to the plasma membrane, triggering the formation of a complex known as the signalosome, which in turns becomes internalized (Bilic et al., 2007; Taelman et al., 2010). The internalization of the signalosome results in inactivation of the $\beta$-catenin destruction complex, and newly synthesized $\beta$-catenin can then translocate to the nucleus, binding to TCF/LEF transcription factors and controlling gene expression (for a review, see (Nusse \& Clevers, 2017)). Importantly, abnormal $\mathrm{Wnt} / \beta$-catenin signaling is commonly associated with cancer initiation (Anastas \& Moon, 2012).

On the other hand, there is a second branch in the Wnt pathway, which comprises several pathways characterized by their independence from $\beta$-catenin stabilization (summarized in (Semenov et al., 2007)). Therefore, this pathway is commonly termed 'non-canonical' (or ' $\beta$ catenin independent') Wnt pathway. Wnt ligands bind to Frizzled receptors and various coreceptors, particularly Ror $1 / 2$, triggering intracellular events that lead to changes in cell behavior (Schlessinger, Hall \& Tolwinski, 2009; van Amerongen, 2012). Wnt ligands are usually classified as canonical or non-canonical, depending on their ability to activate specific Wnt 
77 branches (Kikuchi, Yamamoto \& Kishida, 2007; van Amerongen, Mikels \& Nusse, 2008). For

78

79

80

81

82

83

84

85

86

87

88

89

90

91

92

93

94

95

96

97

98

99

100

101

102

103

104

105

106

107

108

109

110

111

112

113

114 instance, Wnt3a is traditionally regarded as a canonical ligand, whereas Wnt5a is considered a non-canonical ligand. However, the specific pathway activated by each Wnt ligands might ultimately depend on the cellular context, such as combinations of Frizzled receptors and coreceptors (Niehrs, 2012).

The Wnt pathway can interact with other signaling pathways to control cell behavior. In this regard, data published in the last decade has highlighted the strong link between the Wnt pathway and the transcriptional coactivators YAP and TAZ (briefly discussed below). YAP and TAZ are mediators of the Hippo signaling pathway (Moya \& Halder, 2019; Zheng \& Pan, 2019; Dey, Varelas \& Guan, 2020). These proteins have been extensively related to mechanotransduction, but this role might be independent of upstream components of the Hippo pathway (Dupont et al., 2011).

A remarkable observation in some cancer types is the stiffening of the tumor microenvironment (TME) due to extracellular matrix deposition and crosslinking (Kai, Laklai \& Weaver, 2016; Kai, Drain \& Weaver, 2019). As cancer cells invade the TME, they find a stiffened matrix, activating signaling pathways mediated by integrins and YAP/TAZ, among other proteins. When activated, YAP and TAZ translocate to the nucleus, where they bind to TEAD transcription factors to modulate gene expression (Stein et al., 2015; Zanconato et al., 2015). Therefore, a possible functional relationship between YAP, TAZ, and proteins involved in Wnt signaling might link the Wnt pathway to mechanosensing.

As noted above, many reports have shown that the Wnt pathway crosstalks with YAP and TAZ. YAP and TAZ functionally and physically interact with the Wnt machinery, including Dishevelled (Varelas et al., 2010), APC (Cai et al., 2015), $\beta$-catenin (Imajo et al., 2012; Azzolin et al., 2012), and others (Azzolin et al., 2014). Consequently, the literature has focused mainly on the relationship between the Wnt/ $\beta$-catenin pathway and YAP/TAZ. This focus might be explained by the fact that, similar to the involvement of the $\mathrm{Wnt} / \beta$-catenin pathway in cancer, YAP and TAZ have also been linked to this disease, particularly cancer initiation (Zanconato, Cordenonsi \& Piccolo, 2016). However, the non-canonical Wnt pathway, particularly Wnt5a, also plays a crucial role in cancer (Kikuchi et al., 2012). Therefore, it is of great relevance to determine whether Wnt5a might also crosstalk with YAP and TAZ. To date, one report demonstrated that the WNT5A gene is a YAP/TEAD target gene (Park et al., 2015) and that Wnt3a and Wnt5a can activate YAP/TAZ through an 'alternative' pathway independent of LRP5/6 but requiring ROR1/2, G $\alpha_{12 / 13}$ and Rho, thus lending support to this putative crosstalk. In this article, publicly available ChIP-Seq, gene expression, and protein expression data are analyzed to further explore this possible functional relationship. 


\section{Materials \& Methods}

116

117

118

119

120

121

122

123

124

125

126

127

128

129

130

131

132

133

134

135

136

137

138

139

140

141

142

143

144

145

146

147

148

149

150

151

152

153

154

\section{Analysis of the $W N T 5 A$ TSS upstream sequence}

The CistromeDB database allows querying for TFs likely binding to regions upstream the transcriptional start site (TSS) of a given gene (Mei et al., 2017; Zheng et al., 2019). A region $\sim 10 \mathrm{~kb}$ upstream of the TSS of the WNT5A gene was analyzed using the 'ToolKit' feature, querying for 'Transcription factor, chromatin regulator,' employing the NM_003392 transcript for analysis.

As a reference value to compare the TFBSs found in the $W N T 5 A$ gene, the $C C N 2$ gene, encoding for the Connective Tissue Growth Factor (CTGF) protein, was analyzed using CistromeDB. CCN2 is an established TEAD target gene (Zhao et al., 2008). The top peaks found for either YAP1 or TEAD1/4 binding sites were retrieved. The values obtained are, respectively: YAP1, 0.659; TEAD1, 0.626; TEAD4, 0.757.

The ChIP-Atlas (Oki et al., 2018) integrates publicly available ChIP-seq data. The 'Peak Browser' feature was used to search for transcription factors (TFs) or chromatin marks (H3K27ac, H3K4me1, and H3K4me3), selecting "All cell types" and a threshold for significance $=50$. The data was mapped onto the IGV genome browser (Thorvaldsdottir, Robinson \& Mesirov, 2013), spanning a region of $\sim 10 \mathrm{~kb}$ (chr3:55,520,700-55,530,700). The same region was analyzed with the ECR browser (Ovcharenko et al., 2004) to search for similarity between the WNT5A gene and the corresponding gene in the species indicated in the main text, retrieving percent identity plots (PIPs) for evolutionary conserved regions (ECRs) and using the default parameters (minimum ECR identity $=70 \%$; minimum ECR length $=100 \mathrm{pb}$ ). Finally, the KnockTF database (Feng et al., 2020) was queried to search for publicly available experiments correlating the knockdown of TEAD TFs with changes in WNT5A expression.

\section{Gene and protein expression data}

For analysis of gene expression, the online web tools TIMER (version 2.0) (Li et al., 2017b) and GEPIA (version 2.0) (Tang et al., 2019) were used. In TIMER, the 'Gene Correlation' module was used. WNT5A was selected as the 'interested' gene, and the expression of $Y A P 1$, adjusted by tumor purity, was analyzed. A heatmap depicting partial Spearman rho values (degree of correlation between WNT5A and YAP1) was obtained. Of note, only tumor expression data is available for the cancer types with the highest correlation values. In GEPIA, a 'Correlation Analysis' was performed, using either single genes (WNT5A, YAP1) or gene signatures ( $C T G F$ plus $A N K R D 1)$. In each case, Spearman correlation coefficients were computed. Testicular Germ Cell Tumors (TGCT), PAAD (Pancreatic Adenocarcinoma), and BRCA (Breast Invasive Carcinoma) tumor types were evaluated. Since TCGA 'Normal' data was not available for TGCT, only GTEx tissue data was used for tumor/normal comparisons to maintain consistency across the analysis. 
155

156

157

158

159

160

161

162

163

164

165

166

167

168

169

170

171

172

173

174

175

176

177

178

179

180

181

182

183

184

185

186

187

188

189

190

191

192

193

194

For protein expression data, the cBioPortal (Cerami et al., 2012; Gao et al., 2013) and The Cancer Proteome Atlas (TCPA) (Li et al., 2013, 2017a) tools were used. In cBioPortal, one TGCT (TCGA PanCancer Atlas) study was queried for WNT5A and YAP1, using a z-score threshold $= \pm 1.0$ for both mRNA (relative to diploid samples, RNA Seq V2 RSEM) and protein (Reverse Phase protein Arrays, RPPA) expression (149 samples). The Spearman and Pearson correlation coefficients and their respective p-values were computed automatically by cBioPortal. In TCPA, the 'Correlation Analysis' option was used to query the TCGA datasets (TGCT, 118 samples; PAAD, 105 samples; BRCA, 901 samples). The graphs showing the correlation between YAP1 and phosphorylated JNK (pJNK) or AKT (pAKT) were downloaded, and the statistical information (Spearman correlation coefficients) was retrieved from the respective data tables.

\section{Results}

To corroborate whether $W N T 5 A$ expression is modulated by YAP, publicly available ChIPSeq data was first explored, using CistromeDB. A region spanning $\sim 10 \mathrm{~kb}$ upstream the transcription start site (TSS) of the WNT5A gene was analyzed. CistromeDB reveals a subset of TFs with high regulatory potential (RP) score (Fig. 1A). Notably, YAP1 was among the hits retrieved by the analysis, with two binding sites with RP values ranging from 0.48 to 0.67 (Fig. 1A). These values are similar to those found in the well-established YAP/TEAD target gene CCN2/CTGF (see 'Materials \& Methods'). CistromeDB also reveals binding sites for TEAD1 and TEAD4, albeit with low RP scores (the top RP scores were 0.39 for TEAD1, and 0.28 for TEAD4). LATS2 has also been shown to be a YAP/TEAD target gene (Moroishi et al., 2015; Molina-Castro et al., 2020). Analysis of the LATS2 gene in CistromeDB also confirms binding sites for TEAD1, with RP scores ranging from 0.3 to 0.64 , similar to the values observed for WNT5A (Fig. 1B). Interestingly, the analysis using CistromeDB also reveals YAP binding sites, with a high RP value, for the YAP1 gene (Fig. 1C), suggesting that YAP1 might self-regulate its expression through TEAD-mediated transcription. Studies reporting ChIP-Seq analysis have shown that the YAP1 gene might be a YAP/TEAD target gene [for instance, see supplementary information in (Stein et al., 2015; Zanconato et al., 2015)].

To further corroborate the analysis presented above, publicly available ChIP-Seq data was analyzed using the ChIP-Atlas. This analysis reveals two regions with potential binding sites for YAP1, as well as for TEAD1 and TEAD4, upstream of the WNT5A gene (Fig. 2A). It has been reported that YAP/TAZ and AP-1 TFs co-occupy the same genomic regions in a majority of TEAD target genes (Zanconato et al., 2015). Interestingly, the AP-1 transcription factors JUN and FOS also overlap with these YAP1 and TEAD1/4 potential binding sites (Fig. 2A), defining two distinctive potential regulatory regions.

Acetylation of histone $\mathrm{H} 3$ at lysine $27(\mathrm{H} 3 \mathrm{~K} 27 \mathrm{ac})$ as a signature of active enhancers is positively correlated with TEAD binding (Stein et al., 2015), while Zanconato and colleagues used the presence of $\mathrm{H} 3 \mathrm{~K} 4 \mathrm{me} 1$ peaks not overlapping with $\mathrm{H} 3 \mathrm{~K} 4 \mathrm{me} 3$ to identify enhancers (Zanconato 
195

196

197

198

199

200

201

202

203

204

205

206

207

208

209

210

211

212

213

214

215

216

217

218

219

220

221

222

223

224

225

226

227

228

229

230

231

232

233

234

et al., 2015). Mapping H3K27ac, H3K4me1, and H3K4me3 data to the upstream genomic region of $W N T 5 A$ on the IGV browser reveal partial overlap with YAP1, TEAD1, TEAD4, JUN, and FOS (Fig. 2A). H3K27ac extensively marked the region under analysis. Of note, one of these regions is well-conserved in mice and rats (Fig. 2B, dashed box). Finally, using the KnockTF database to search for genes down-regulated after knockdown of TEAD TFs indicates that WNT5A is among the most down-regulated genes after TEAD4 knockdown in the SNU216 gastric cell line (Fig. 2C). It is worth noting that this data comes from an independent study (Lim et al., 2014), published before the article from Park and colleagues (Park et al., 2015).

In summary, in silico analysis corroborates that $W N T 5 A$ is a TEAD target gene. Moreover, these results indicate that YAP might modulate WNT5A expression in different contexts and suggest the existence of a regulatory circuit comprising Wnt5a, YAP, and possibly LATS2. Given that both Wnt5a and abnormal YAP/TAZ signaling have been linked to cancer (see 'Introduction'), this relationship was further explored using cancer gene expression data.

Analysis of gene expression data using TIMER 2.0 shows a moderate-to-strong correlation between $W N T 5 A$ and YAPI in several cancer types (Fig. 3A). Interestingly, the strongest correlation was observed for Testicular Germ Cell Tumors (TGCT; Spearman correlation $=0.7$ ), a cancer type with little information about the involvement of the Wnt pathway (see 'Discussion'). A moderate (Spearman correlation value $>0.5$ ) correlation was also observed for PAAD (Pancreatic Adenocarcinoma), THYM (Thymoma), UVM (Uveal Melanoma), UCS (Uterine Carcinosarcoma), SKCM-Primary (Skin Cutaneous Melanoma), BRCA-LumA (Breast Invasive Carcinoma) and DLBC (Diffuse Large B-Cell Lymphoma) (Fig. 3A). This correlation was corroborated for TGCT, BRCA and PAAD (Fig. 3B-D). Importantly, there was a lower correlation between WNT5A and YAP1 in normal tissues for testis, breast, and pancreas (Fig. 3E-G).

Wnt5a has been reported to either activate or inhibit Wnt/ $\beta$-catenin signaling in several cellular contexts (Torres et al., 1996; He et al., 1997; Ishitani et al., 1999, 2003; Topol et al., 2003; Westfall et al., 2003; Mikels \& Nusse, 2006). By modulating the Wnt/ $\beta$-catenin pathway, Wnt5a might release YAP from the $\beta$-catenin destruction complex, allowing YAP to promote the expression of TEAD target genes. Alternatively, Wnt5a might promote the assembly of the $\beta$ catenin destruction complex, thus sequestering YAP and TAZ, concomitantly abolishing the expression of TEAD target genes.

In consequence, it was evaluated whether $W N T 5 A$ levels correlated with TEAD target gene expression in the cancer types where a moderate to strong correlation was observed, using GEPIA. For TGCT, a strong correlation (Spearman correlation $=0.69$ ) between $W N T 5 A$ and a gene signature composed of $C T G F$ and $A N K R D 1$ (two well-established TEAD target genes) was observed. In contrast, only weak correlations were observed for PAAD and BRCA cancer (Fig. 4). Notably, when comparing cancer and normal (GTEx data) expression, this correlation was greatly lost in both testis and pancreas (Fig. 4). In addition, the analysis of gene and protein expression data in TGCT showed that high WNT5A levels correlated with high YAP1 protein expression (Fig. 5A). Therefore, these results suggest that, at least in TGCT, Wnt5a might promote YAP/TAZ stability and activity. In addition, the correlation between WNT5A and the CTGF/ANKRDI

Peer] reviewing PDF | (2020:09:53301:1:2:NEW 16 Dec 2020) 
235 signature as a readout for YAP/TEAD activity might be correlated with cancer progression in both 236 TGCT and PAAD.

237 The activation of the Wnt/ $\beta$-catenin signaling pathway leads to specific and well238 established readouts, such as phosphorylation of LRP6 and nuclear accumulation of $\beta$-catenin. On 239 the contrary, signaling mediated by non-canonical Wnt ligands activates less-specific readouts, 240 such as JNK or AKT phosphorylation. The TCGA contains protein (RPPA) expression data for 241 approximately 300 proteins, thus allowing to perform preliminary exploration of the activation of 242 certain signaling pathways. Data from the TCPA was explored for TGCT, BRCA, and PAAD 243 cancer. Interestingly, both JNK (pT183, Y185) and AKT (pT308) phosphorylation were highly 244 correlated with YAP expression in TGCT cancer (Fig. 5B), but not in BRCA (Spearman's rank 245 correlation coefficient, $\mathrm{pJNK}=0.12713$; $\mathrm{pAKT}=0.19721$; $\mathrm{p}$-values, $\mathrm{pJNK}=0.00016438$; $\mathrm{pAKT}$ $246=4.1085 \mathrm{e}-9$ ) or PAAD (Spearman's rank correlation coefficient, $\mathrm{pJNK}=-0.045635$; $\mathrm{pAKT}=$ 247 0.0853; p-values, not significant). These results must be interpreted with caution since high Wnt5a 248 expression might lead to activation of other intracellular effectors, such as Rho GTPases, in these 249 cancer types (Schlessinger, Hall \& Tolwinski, 2009).

250 Collectively, the analysis presented in this article suggests that WNT5A expression is 251 modulated by YAP/TEAD in several cancer types, although likely leading to different cellular 252 outcomes depending on the tissue or cell type. More importantly, WNT5A correlates with a $253 \mathrm{YAP} / \mathrm{TEAD}$ signature and $\mathrm{pJNK} / \mathrm{pAKT}$ in testicular germ cell cancer, thus providing potentially 254 255

256

257

258

259

260

261

262

263

264

265

266

267

268

269

270

271

272

273 novel evidence for a role of the non-canonical Wnt pathway in this cancer type.

\section{Discussion}

To date, most articles assessing the relationship between YAP, TAZ, and the Wnt signaling pathway have focused on the involvement of YAP/TAZ in the Wnt/ $\beta$-catenin signaling branch. Research from several groups has shown that YAP/TAZ interacts with the $\beta$-catenin destruction complex and other Wnt components, as noted above. According to the prevailing model, activation of the $\mathrm{Wnt} / \beta$-catenin pathway leads to the disassembly of the $\beta$-catenin destruction complex, thus releasing YAP and TAZ. In turn, YAP and TAZ dynamically shuttle across the nucleus, to either co-repress or co-activate the transcription of target genes by interacting with TEAD transcription factors (Manning, Kroeger \& Harvey, 2020).

In contrast, the possible interaction between the non-canonical Wnt pathway and YAP/TAZ remains less understood. However, growing evidence suggests that YAP and Wnt5a might functionally interact in cancer (Tu et al., 2019; Luo et al., 2020) and chronic kidney disease (Feng et al., 2018). Interestingly, chronic kidney disease is characterized by increased fibrosis; similarly, cancer progression is also accompanied by an increased stiffening of the TME, due to higher extracellular matrix deposition and collagen crosslinking. This suggests that Wnt5a and YAP/TAZ might functionally interact in certain cellular contexts. However, despite this growing body of evidence, there is a lack of deep mechanistic understanding of how Wnt5a 
274 and YAP might interact. Only one study addressed this interaction, showing that $W N T 5 A$ is a 275 TEAD target gene (Park et al., 2015).

276 Given the relevance of such a relationship, it is desirable to obtain further evidence 277 supporting it. The availability of transcriptomic and proteomic data across cancer types allows 278 surveying for potential correlations between gene signatures. In addition, the growing abundance 279 of ChIP-Seq data facilitates the inquiry of potential regulatory relationships across cell types. 280 This article analyzed publicly available data to corroborate whether YAP might regulate Wnt5a. 281 In agreement with the previously existing observation reported by Park and colleagues (Park et 282 al., 2015), ChIP-Seq data shows YAP/TEAD binding in some cancer cell lines (MSTO-211H, 283 H2052, SF268, and SK-N-SH), according to the datasets included in the ChIP-Seq atlas. It will 284 be interesting to determine whether YAP/TEAD binding to the $W N T 5 A$ regulatory region is a 285 feature of cancer cell lines or if this merely represents a need for additional studies in other cell 286 types.

287

288

289

290

291

292

293

294

295

296

297

298

299

300

301

302

303

304

305

306

307

308

309

310

311

312

313

The data presented here show that an upstream region of the WNT5A gene contains two putative regulatory regions that might be responsible for this regulation. Given that previous reports showed a role for AP-1 TFs in the context of TEAD-dependent gene expression, the analysis presented in this article also employed AP-1 ChIP-Seq data, showing overlap with TEAD binding sites, strongly suggesting that these regions upstream the WNT5A TSS might constitute enhancers. It must be noted, however, that other TFs are likely needed to fine-tune the expression of $W N T 5 A$, thus explaining the results observed by surveying cancer expression data. It must also be noted that the present article does not address other genomic regions, which might also contain regulatory sequences. However, it has been reported that YAP/TAZ/TEAD complexes mostly modulate distant enhancers located beyond 1-2 kb upstream of the TSS (Stein et al., 2015; Zanconato et al., 2015). Also, it must be noted that the WNT5A gene encodes two isoforms, Wnt5a-S (short) and Wnt5a-L (long) (Bauer et al., 2013). Both Wnt5a-S and Wnt5a-L have similar properties, but they differ in functions, including in some cancer types (Bauer et al., 2013; Huang et al., 2017). It will be interesting to determine whether TEAD-mediated modulation intersects with other signaling cues that might modulate the differential expression of these isoforms.

Notwithstanding, gene expression data showed that WNT5A and YAPI expression is moderately-to-strongly correlated in several cancer types. This article focused on three cancer types: breast (BRCA) and pancreatic (PAAD) cancer, due to their clinical relevance; and testicular germ cell (TGCT) cancer, since little is known about the role of the Wnt pathway in this cancer type. For BRCA and PAAD, the analysis presented here showed that, although there is a moderate correlation between WNT5A and YAP1, this does not translate into an increased TEAD signature or JNK/AKT phosphorylation, commonly employed as a readout for noncanonical Wnt signaling. Further research will be needed to determine whether the WNT5A and YAPI correlation has any functional relevance. In this regard, it must be noted that Wnt5a might exert different signaling outcomes. For instance, Wnt5a might modulate integrin adhesion dynamics (Kurayoshi et al., 2006; Matsumoto et al., 2010), while YAP itself also controls the

Peer) reviewing PDF | (2020:09:53301:1:2:NEW 16 Dec 2020) 
314 expression of integrin adhesion components (Nardone et al., 2017). Both BRCA and PAAD are 315 characterized by stiffening of the TME, and thus future research should assess whether Wnt5a 316 and YAP might be involved in this fibrotic response. As noted above, recent evidence also 317 suggests a functional relationship between YAP and Wnt5a in skin melanoma (Luo et al., 2020)

318

319

320

321

322

323

324

325

326

327

328

329

330

331

332

333

334

335

336

337

338

339

340

341

342

343

344

345

346

347

348

349

350

351

352

353 and pancreatic adenocarcinoma (Tu et al., 2019), two cancer types where a moderate correlation between YAPI and WNT5A expression is observed (Figure 3). In the first case, the YAP/Wnt5a signaling axis is likely involved in modulating cell migration, while in the latter, it might be related to tumor growth. The precise molecular mechanisms in both cases remain to be fully elucidated, but this evidence helps to highlight the possible roles that might be regulated by the YAP/Wnt5a module.

The data presented in this article also shows that $W N T 5 A$ levels are correlated with YAP protein levels and a TEAD signature (CTGF and ANKRDI expression). Notably, the correlation between $W N T 5 A$ and the TEAD signature is significantly lost in testis (GTEx) normal data, thus suggesting a potential relevance of this correlation. Moreover, YAP protein expression correlates with $\mathrm{pJNK}$ and pAKT. To date, the evidence regarding testicular germ cell cancer and Wnt signaling is limited to the $\mathrm{Wnt} / \beta$-catenin pathway, although there is no clear role for this pathway in TGCT progression. Analysis of $\beta$-catenin expression and localization suggest that the $\mathrm{Wnt} / \beta$ catenin pathway might be essential for normal spermatogenesis (Young et al., 2020); however, nuclear $\beta$-catenin is not seen in neoplastic germ cells (Chovanec et al., 2018; Young et al., 2020). In contrast, in vitro assays using a seminoma-derived cell line, TCam-2, suggests a possible role of the Wnt/ $\beta$-catenin in cell viability and migration (Young et al., 2020). However, the abovementioned study did not address the role of Wnt5a, and the absence of mechanical and other biochemical signals from the tumor microenvironment might induce different responses in vivo.

On the other hand, comprehensive studies have shown that only a limited number of genes might be correlated with TGCT establishment (Shen et al., 2018). Therefore, the precise role of the Wnt pathway and YAP/TAZ in this cancer type remains to be fully established. Since TGCT are morphologically heterogeneous, and only a few genes have been conclusively correlated with TGCT establishment, perturbations in signaling pathways, rather than driving mutations, might likely play a crucial role in this disease. Therefore, the results relative to TGCT presented in this article might be of special interest.

Finally, it must be stressed that this article presents some limitations. The data obtained here must be properly explored both in vitro and in vivo. In this regard, the reports cited above offer possible models to explore a mechanistic relationship between YAP and Wnt5a. Secondly, the analysis presented in this article might be further expanded to include a Hippo signature (Wang et al., 2018). In addition, protein expression data related to the $\mathrm{Wnt} / \beta$-catenin pathway (such as GSK-3 $\beta$ phosphorylation) must also be examined. 
354

355

356

357

358

359

360

361

362

363

364

365

366

367

368

369

370

371

372

373

374

375

376

377

378

379

380

381

382

383

384

385

386

387

388

389

390

391

392

393

\section{Conclusions}

Altogether, the observations presented here suggest the further need to study the functional relationship between YAP/TAZ and the non-canonical Wnt pathway, particularly in the context of cancer. In addition, the crosstalk between YAP/TAZ and the Wnt pathway should be assessed from a systems biology perspective, considering possible feedback mechanisms and regulatory circuits, which might be perturbed in the context of cancer and other diseases.

\section{Figure Legends}

Figure 1. Binding sites with high regulatory potential scores for WNT5A, LATS2, and YAP1. Data was obtained using CistromeDB, spanning a region of $\sim 10 \mathrm{~kb}$ upstream the transcription start site (TSS) of the WNT5A (A), LATS2 (B), and YAP1 (C) genes. YAP/TEAD proteins are highlighted in bold.

Figure 2. YAP/TEAD binding sites upstream the WNT5A transcription start site (TSS). (A) ChIP-Seq data mapped onto a region spanning $\sim 10 \mathrm{~kb}$ upstream of the transcription start site (TSS) of the WNT5A gene, using the IGC browser. The data for each co-factor (YAP1), transcription factors (TEAD1, TEAD4, JUN, FOS), and histone modifications (H3K27ac, $\mathrm{H} 3 \mathrm{~K} 4 \mathrm{me}$, and $\mathrm{H} 3 \mathrm{~K} 4 \mathrm{me} 3$ ), correspond to separate experiments, represented by different colors. See the main text for details. (B) Evolutionary conserved regions (ECRs) between the human, mouse, and rat Wnt5a gene. The same region shown in (A) was analyzed using the ECR Browser. The dashed box shows the matching region enriched for YAP/TEAD binding, according to ChIP-Seq data. (C) Data from the specified KnockTF dataset showing WNT5A (in bold) as a downregulated gene after TEAD4 knockdown.

Figure 3. Correlation between $W N T 5 A$ and $Y A P 1$ expression across cancer types. (A) Heat map (Spearman correlation coefficients) retrieved from TIMER, showing the correlation between WNT5A and YAPI expression across the indicated cancer types (ACC, Adrenocortical carcinoma; BLCA, Bladder Urothelial Carcinoma; BRCA, Breast invasive carcinoma; CESC, Cervical squamous cell carcinoma and endocervical adenocarcinoma; $\mathrm{CHOL}$, Cholangiocarcinoma; COAD, Colon adenocarcinoma; DLBC, Lymphoid Neoplasm Diffuse Large B-cell Lymphoma; ESCA, Esophageal carcinoma; GBM, Glioblastoma multiforme; HNSC, Head and Neck squamous cell carcinoma; KICH, Kidney Chromophobe; KIRC, Kidney renal clear cell carcinoma; KIRP, Kidney renal papillary cell carcinoma; LGG, Brain Lower Grade Glioma; LIHC, Liver hepatocellular carcinoma; LUAD, Lung adenocarcinoma; LUSC, Lung squamous cell carcinoma; MESO, Mesothelioma; OV, Ovarian serous cystadenocarcinoma; PAAD, Pancreatic adenocarcinoma; PCPG, Pheochromocytoma and Paraganglioma; PRAD, Prostate adenocarcinoma; READ, Rectum adenocarcinoma; SARC, Sarcoma; SKCM, Skin Cutaneous Melanoma; STAD, Stomach adenocarcinoma; TGCT, 
394 Testicular Germ Cell Tumors; THCA, Thyroid carcinoma; THYM, Thymoma; UCEC, Uterine 395 Corpus Endometrial Carcinoma; UCS, Uterine Carcinosarcoma; UVM, Uveal Melanoma). (B-G)

396 Correlation between $W N T 5 A$ and YAP1 expression in the indicated cancer types, according to 397 data from GEPIA, using tumor (top; B-D) and GTEx normal (bottom; E-G) data. Spearman 398 correlation coefficients were automatically computed and are shown at the top of each plot. 399 TPM, transcript per million.

400

401

402

403

404

405

406

407

408

409

410

411

412

413

414

415

416

417

418

419

420

421

422

423

424

425

426

427

428

429

430

431

432

433

434

435

Figure 4. Correlation between WNT5A expression and a YAP/TEAD gene signature. Tumor (top) and the corresponding GTEx normal tissue (bottom) data are shown for the indicated cancer types, and the correlation between $W N T 5 A$ and the 'YAP/TEAD' signature (CTGF plus $A N K R D 1)$ was estimated using the 'Gene Signature' option in GEPIA. Spearman correlation coefficients were automatically computed and are shown at the top of each plot.

\section{Figure 5. Correlation between $W N T 5 A$ and YAP protein expression and JNK/AKT} phosphorylation in Testicular Germ Cell Tumors. (A) Correlation between WNT5A and YAP protein expression in TGCT cancer. The data was retrieved from cBioPortal (see 'Methods' for the parameters used for the analysis). (B) Correlation between YAP protein expression and JNK (left) and AKT (right) protein phosphorylation, according to The Cancer Proteome Atlas.

\section{References}

van Amerongen R. 2012. Alternative Wnt Pathways and Receptors. Cold Spring Harbor Perspectives in Biology 4:a007914-a007914. DOI: 10.1101/cshperspect.a007914.

van Amerongen R, Mikels A, Nusse R. 2008. Alternative Wnt Signaling Is Initiated by Distinct

Receptors. Science Signaling 1:re9-re9. DOI: 10.1126/scisignal.135re9.

Anastas JN, Moon RT. 2012. WNT signalling pathways as therapeutic targets in cancer. Nature Reviews Cancer 13:11-26.

Azzolin L, Panciera T, Soligo S, Enzo E, Bicciato S, Dupont S, Bresolin S, Frasson C, Basso G, Guzzardo V, Fassina A, Cordenonsi M, Piccolo S. 2014. YAP/TAZ Incorporation in the $\beta$-Catenin Destruction Complex Orchestrates the Wnt Response. CELL 158:157-170.

Azzolin L, Zanconato F, Bresolin S, Forcato M, Basso G, Bicciato S, Cordenonsi M, Piccolo S. 2012.

Role of TAZ as Mediator of Wnt Signaling. CELL:1-14.

Bauer M, Bénard J, Gaasterland T, Willert K, Cappellen D. 2013. WNT5A Encodes Two Isoforms with Distinct Functions in Cancers. PLOS ONE 8:e80526.

Bilic J, Huang Y-L, Davidson G, Zimmermann T, Cruciat C-M, Bienz M, Niehrs C. 2007. Wnt Induces LRP6 Signalosomes and Promotes Dishevelled-Dependent LRP6 Phosphorylation. Science 316:16191622. DOI: $10.1126 /$ science. 1137065.

Cai J, Maitra A, Anders RA, Taketo MM, Pan D. 2015. $\beta$-Catenin destruction complex-independent regulation of Hippo-YAP signaling by APC in intestinal tumorigenesis. Genes \& Development 29:14931506.

Cerami E, Gao J, Dogrusoz U, Gross BE, Sumer SO, Aksoy BA, Jacobsen A, Byrne CJ, Heuer ML,

Peer) reviewing PDF | (2020:09:53301:1:2:NEW 16 Dec 2020) 
436 Larsson E, Antipin Y, Reva B, Goldberg AP, Sander C, Schultz N. 2012. The cBio Cancer Genomics

437 Portal: An Open Platform for Exploring Multidimensional Cancer Genomics Data: Figure 1. Cancer

438 Discovery 2:401-404. DOI: 10.1158/2159-8290.CD-12-0095.

439 Chovanec M, Cierna Z, Miskovska V, Machalekova K, Kalavska K, Rejlekova K, Svetlovska D, Macak

440 D, Spanik S, Kajo K, Babal P, Mego M, Mardiak J. 2018. $\beta$ catenin is a marker of poor clinical

441 characteristics and suppressed immune infiltration in testicular germ cell tumors. BMC cancer 18:1062.

442 DOI: 10.1186/s12885-018-4929-x.

443 Dey A, Varelas X, Guan K-L. 2020. Targeting the Hippo pathway in cancer, fibrosis, wound healing and 444 regenerative medicine. Nature Reviews Drug Discovery 19:480-494. DOI: 10.1038/s41573-020-0070-z.

445 Dupont S, Morsut L, Aragona M, Enzo E, Giulitti S, Cordenonsi M, Zanconato F, Le Digabel J, Forcato

446 M, Bicciato S, Elvassore N, Piccolo S. 2011. Role of YAP/TAZ in mechanotransduction. Nature

$447 \quad 474: 179-183$.

448 Feng Y, Liang Y, Zhu X, Wang M, Gui Y, Lu Q, Gu M, Xue X, Sun X, He W, Yang J, Johnson RL, Dai

449 C. 2018 . The signaling protein Wnt5a promotes TGF $\beta 1$-mediated macrophage polarization and kidney

450 fibrosis by inducing the transcriptional regulators Yap/Taz. Journal of Biological Chemistry 293:19290-

451 19302. DOI: 10.1074/jbc.RA118.005457.

452 Feng C, Song C, Liu Y, Qian F, Gao Y, Ning Z, Wang Q, Jiang Y, Li Y, Li M, Chen J, Zhang J, Li C.

453 2020. KnockTF: a comprehensive human gene expression profile database with knockdown/knockout of

454 transcription factors. Nucleic Acids Research 48:D93-D100. DOI: 10.1093/nar/gkz881.

455 Gao J, Aksoy BA, Dogrusoz U, Dresdner G, Gross B, Sumer SO, Sun Y, Jacobsen A, Sinha R, Larsson E, 456 Cerami E, Sander C, Schultz N. 2013. Integrative Analysis of Complex Cancer Genomics and Clinical

457 Profiles Using the cBioPortal. Science Signaling 6:pl1-pl1. DOI: 10.1126/scisignal.2004088.

458 He X, Saint-Jeannet JP, Wang Y, Nathans J, Dawid I, Varmus H. 1997. A member of the Frizzled protein 459 family mediating axis induction by Wnt-5A. Science 275:1652-1654.

460 Huang T-C, Lee P-T, Wu M-H, Huang C-C, Ko C-Y, Lee Y-C, Lin D-Y, Cheng Y-W, Lee K-H. 2017.

461 Distinct roles and differential expression levels of Wnt5a mRNA isoforms in colorectal cancer cells.

462 PLOS ONE 12:e0181034. DOI: 10.1371/journal.pone.0181034.

463 Imajo M, Miyatake K, Iimura A, Miyamoto A, Nishida E. 2012. A molecular mechanism that links Hippo 464 signalling to the inhibition of Wnt/\&beta;-catenin signalling. The EMBO Journal 31:1109-1122.

465 Ishitani T, Kishida S, Hyodo-Miura J, Ueno N, Yasuda J, Waterman M, Shibuya H, Moon RT, Ninomiya-

466 Tsuji J, Matsumoto K. 2003. The TAK1-NLK Mitogen-Activated Protein Kinase Cascade Functions in

467 the Wnt-5a/Ca2+ Pathway To Antagonize Wnt/ß-Catenin Signaling. Molecular and Cellular Biology

468 23:131-139. DOI: 10.1128/MCB.23.1.131-139.2003.

469 Ishitani T, Ninomiya-Tsuji J, Nagai S, Nishita M, Meneghini M, Barker N, Waterman M, Bowerman B,

470 Clevers H, Shibuya H, Matsumoto K. 1999. The TAK1-NLK-MAPK-related pathway antagonizes

471 signalling between beta-catenin and transcription factor TCF. Nature 399:798-802. DOI: 10.1038/21674.

472 Kai F, Drain AP, Weaver VM. 2019. The Extracellular Matrix Modulates the Metastatic Journey.

473 Developmental Cell 49:332-346. DOI: 10.1016/j.devcel.2019.03.026.

474 Kai F, Laklai H, Weaver VM. 2016. Force Matters: Biomechanical Regulation of Cell Invasion and

475 Migration in Disease. Trends in Cell Biology.

476 Kikuchi A, Yamamoto H, Kishida S. 2007. Multiplicity of the interactions of Wnt proteins and their

477 receptors. Cellular Signalling 19:659-671. DOI: 10.1016/j.cellsig.2006.11.001.

478 Kikuchi A, Yamamoto H, Sato A, Matsumoto S. 2012. Wnt5a: its signalling, functions and implication in 479 diseases. Acta physiologica (Oxford, England) 204:17-33. 
480 Kurayoshi M, Oue N, Yamamoto H, Kishida M, Inoue A, Asahara T, Yasui W, Kikuchi A. 2006.

481 Expression of Wnt-5a Is Correlated with Aggressiveness of Gastric Cancer by Stimulating Cell Migration

482 and Invasion. Cancer Research 66:10439-10448.

483 Li J, Akbani R, Zhao W, Lu Y, Weinstein JN, Mills GB, Liang H. 2017a. Explore, Visualize, and

484 Analyze Functional Cancer Proteomic Data Using the Cancer Proteome Atlas. Cancer Research 77:e51-

485 e54. DOI: 10.1158/0008-5472.CAN-17-0369.

486 Li T, Fan J, Wang B, Traugh N, Chen Q, Liu JS, Li B, Liu XS. 2017b. TIMER: A Web Server for

487 Comprehensive Analysis of Tumor-Infiltrating Immune Cells. Cancer Research 77:e108-e110. DOI:

488 10.1158/0008-5472.CAN-17-0307.

489 Li J, Lu Y, Akbani R, Ju Z, Roebuck PL, Liu W, Yang J-Y, Broom BM, Verhaak RGW, Kane DW,

490 Wakefield C, Weinstein JN, Mills GB, Liang H. 2013. TCPA: a resource for cancer functional proteomics 491 data. Nature Methods 10:1046-1047.

492 Lim B, Park J-L, Kim H-J, Park Y-K, Kim J-H, Sohn HA, Noh S-M, Song K-S, Kim W-H, Kim YS, Kim 493 S-Y. 2014. Integrative genomics analysis reveals the multilevel dysregulation and oncogenic

494 characteristics of TEAD4 in gastric cancer. Carcinogenesis 35:1020-1027. DOI: 10.1093/carcin/bgt409.

495 Logan CY, Nusse R. 2004. The Wnt signaling pathway in development and disease. Annual Review of

496 Cell and Developmental Biology 20:781-810. DOI: 10.1146/annurev.cellbio.20.010403.113126.

497 Luo C, Balsa E, Perry EA, Liang J, Tavares CD, Vazquez F, Widlund HR, Puigserver P. 2020.

498 H3K27me3-mediated PGC1 $\alpha$ gene silencing promotes melanoma invasion through WNT5A and YAP.

499 Journal of Clinical Investigation 130:853-862. DOI: 10.1172/JCI130038.

500 Manning SA, Kroeger B, Harvey KF. 2020. The regulation of Yorkie, YAP and TAZ: new insights into

501 the Hippo pathway. Development 147:dev179069. DOI: 10.1242/dev.179069.

502 Matsumoto S, Fumoto K, Okamoto T, Kaibuchi K, Kikuchi A. 2010. Binding of APC and dishevelled

503 mediates Wnt5a-regulated focal adhesion dynamics in migrating cells. The EMBO Journal 29:1192-

5041204.

505 Mei S, Qin Q, Wu Q, Sun H, Zheng R, Zang C, Zhu M, Wu J, Shi X, Taing L, Liu T, Brown M, Meyer

506 CA, Liu XS. 2017. Cistrome Data Browser: a data portal for ChIP-Seq and chromatin accessibility data in

507 human and mouse. Nucleic Acids Research 45:D658-D662. DOI: 10.1093/nar/gkw983.

508 Mikels AJ, Nusse R. 2006. Purified Wnt5a protein activates or inhibits beta-catenin-TCF signaling

509 depending on receptor context. PLOS Biology 4:e115.

510 Molina-Castro SE, Tiffon C, Giraud J, Boeuf H, Sifre E, Giese A, Belleannée G, Lehours P, Bessède E,

511 Mégraud F, Dubus P, Staedel C, Varon C. 2020. The Hippo Kinase LATS2 Controls Helicobacter pylori-

512 Induced Epithelial-Mesenchymal Transition and Intestinal Metaplasia in Gastric Mucosa. Cellular and

513 Molecular Gastroenterology and Hepatology 9:257-276. DOI: 10.1016/j.jcmgh.2019.10.007.

514 Moroishi T, Park HW, Qin B, Chen Q, Meng Z, Plouffe SW, Taniguchi K, Yu F-X, Karin M, Pan D,

515 Guan K-L. 2015. A YAP/TAZ-induced feedback mechanism regulates Hippo pathway homeostasis.

516 Genes \& Development 29:1271-1284. DOI: 10.1101/gad.262816.115.

517 Moya IM, Halder G. 2019. Hippo-YAP/TAZ signalling in organ regeneration and regenerative medicine.

518 Nature Reviews Molecular Cell Biology 20:211-226. DOI: 10.1038/s41580-018-0086-y.

519 Nardone G, Oliver-De La Cruz J, Vrbsky J, Martini C, Pribyl J, Skládal P, Pešl M, Caluori G, Pagliari S,

520 Martino F, Maceckova Z, Hajduch M, Sanz-Garcia A, Pugno NM, Stokin GB, Forte G. 2017. YAP

521 regulates cell mechanics by controlling focal adhesion assembly. Nature Communications 8:15321. DOI:

$52210.1038 /$ ncomms 15321.

523 Niehrs C. 2012. The complex world of WNT receptor signalling. Nature Reviews Molecular Cell Biology

Peer] reviewing PDF | (2020:09:53301:1:2:NEW 16 Dec 2020) 
524

525

526

527

528

529

530

531

532

533

534

535

536

537

538

539

540

541

542

543

544

545

546

547

548

549

550

551

552

553

554

555

556

557

558

559

560

561

562

563

564

565

566

567

13:767-779.

Nusse R, Clevers H. 2017. Wnt/ $\beta$-Catenin Signaling, Disease, and Emerging Therapeutic Modalities. Cell 169:985-999. DOI: 10.1016/j.cell.2017.05.016.

Oki S, Ohta T, Shioi G, Hatanaka H, Ogasawara O, Okuda Y, Kawaji H, Nakaki R, Sese J, Meno C. 2018. ChIP-Atlas: a data-mining suite powered by full integration of public ChIP-seq data. EMBO reports 19. DOI: $10.15252 / \mathrm{embr} .201846255$.

Ovcharenko I, Nobrega MA, Loots GG, Stubbs L. 2004. ECR Browser: a tool for visualizing and accessing data from comparisons of multiple vertebrate genomes. Nucleic Acids Research 32:W280W286. DOI: 10.1093/nar/gkh355.

Park HW, Kim YC, Yu B, Moroishi T, Mo J-S, Plouffe SW, Meng Z, Lin KC, Yu F-X, Alexander CM, Wang C-Y, Guan K-L. 2015. Alternative Wnt Signaling Activates YAP/TAZ. Cell 162:780-794. DOI: 10.1016/j.cell.2015.07.013.

Schlessinger K, Hall A, Tolwinski N. 2009. Wnt signaling pathways meet Rho GTPases. Genes \& Development 23:265-277. DOI: 10.1101/gad.1760809.

Semenov MV, Habas R, MacDonald BT, He X. 2007. SnapShot: Noncanonical Wnt Signaling Pathways. Cell 131:1378.e1-1378.e2. DOI: 10.1016/j.cell.2007.12.011.

Shen H, Shih J, Hollern DP, Wang L, Bowlby R, Tickoo SK, Thorsson V, Mungall AJ, Newton Y, Hegde AM, Armenia J, Sánchez-Vega F, Pluta J, Pyle LC, Mehra R, Reuter VE, Godoy G, Jones J, Shelley CS, Feldman DR, Vidal DO, Lessel D, Kulis T, Cárcano FM, Leraas KM, Lichtenberg TM, Brooks D, Cherniack AD, Cho J, Heiman DI, Kasaian K, Liu M, Noble MS, Xi L, Zhang H, Zhou W, ZenKlusen JC, Hutter CM, Felau I, Zhang J, Schultz N, Getz G, Meyerson M, Stuart JM, Cancer Genome Atlas Research Network, Akbani R, Wheeler DA, Laird PW, Nathanson KL, Cortessis VK, Hoadley KA. 2018. Integrated Molecular Characterization of Testicular Germ Cell Tumors. Cell Reports 23:3392-3406. DOI: 10.1016/j.celrep.2018.05.039.

Stein C, Bardet AF, Roma G, Bergling S, Clay I, Ruchti A, Agarinis C, Schmelzle T, Bouwmeester T, Schübeler D, Bauer A. 2015. YAP1 Exerts Its Transcriptional Control via TEAD-Mediated Activation of Enhancers. PLoS genetics 11:e1005465.

Taelman VF, Dobrowolski R, Plouhinec J-L, Fuentealba LC, Vorwald PP, Gumper I, Sabatini DD, De Robertis EM. 2010. Wnt Signaling Requires Sequestration of Glycogen Synthase Kinase 3 inside Multivesicular Endosomes. Cell 143:1136-1148. DOI: 10.1016/j.cell.2010.11.034.

Tang Z, Kang B, Li C, Chen T, Zhang Z. 2019. GEPIA2: an enhanced web server for large-scale expression profiling and interactive analysis. Nucleic Acids Research 47:W556-W560. DOI: 10.1093/nar/gkz430.

Thorvaldsdottir H, Robinson JT, Mesirov JP. 2013. Integrative Genomics Viewer (IGV): highperformance genomics data visualization and exploration. Briefings in Bioinformatics 14:178-192. DOI: 10.1093/bib/bbs017.

Topol L, Jiang X, Choi H, Garrett-Beal L, Carolan PJ, Yang Y. 2003. Wnt-5a inhibits the canonical Wnt pathway by promoting GSK-3-independent $\beta$-catenin degradation. Journal of Cell Biology 162:899-908. DOI: $10.1083 /$ jcb.200303158.

Torres MA, Yang-Snyder JA, Purcell SM, DeMarais AA, McGrew LL, Moon RT. 1996. Activities of the Wnt-1 class of secreted signaling factors are antagonized by the Wnt-5A class and by a dominant negative cadherin in early Xenopus development. The Journal of Cell Biology 133:1123-1137. DOI: 10.1083/jcb.133.5.1123.

Tu B, Yao J, Ferri-Borgogno S, Zhao J, Chen S, Wang Q, Yan L, Zhou X, Zhu C, Bang S, Chang Q, 
568 Bristow CA, Kang Y, Zheng H, Wang H, Fleming JB, Kim M, Heffernan TP, Draetta GF, Pan D, Maitra

569 A, Yao W, Gupta S, Ying H. 2019. YAP1 oncogene is a context-specific driver for pancreatic ductal

570

571

572

573

574

575

576

577

578

579

580

581

582

583 adenocarcinoma. JCI Insight 4:e130811. DOI: 10.1172/jci.insight.130811.

Varelas X, Miller BW, Sopko R, Song S, Gregorieff A, Fellouse FA, Sakuma R, Pawson T, Hunziker W, McNeill H, Wrana JL, Attisano L. 2010. The Hippo pathway regulates Wnt/beta-catenin signaling. Developmental Cell 18:579-591.

Wang Y, Xu X, Maglic D, Dill MT, Mojumdar K, Ng PK-S, Jeong KJ, Tsang YH, Moreno D, Bhavana VH, Peng X, Ge Z, Chen H, Li J, Chen Z, Zhang H, Han L, Du D, Creighton CJ, Mills GB, Camargo F, Liang H, Caesar-Johnson SJ, Demchok JA, Felau I, Kasapi M, Ferguson ML, Hutter CM, Sofia HJ, Tarnuzzer R, Wang Z, Yang L, Zenklusen JC, Zhang J (Julia), Chudamani S, Liu J, Lolla L, Naresh R, Pihl T, Sun Q, Wan Y, Wu Y, Cho J, DeFreitas T, Frazer S, Gehlenborg N, Getz G, Heiman DI, Kim J, Lawrence MS, Lin P, Meier S, Noble MS, Saksena G, Voet D, Zhang H, Bernard B, Chambwe N, Dhankani V, Knijnenburg T, Kramer R, Leinonen K, Liu Y, Miller M, Reynolds S, Shmulevich I, Thorsson V, Zhang W, Akbani R, Broom BM, Hegde AM, Ju Z, Kanchi RS, Korkut A, Li J, Liang H, Ling S, Liu W, Lu Y, Mills GB, Ng K-S, Rao A, Ryan M, Wang J, Weinstein JN, Zhang J, Abeshouse A, Armenia J, Chakravarty D, Chatila WK, de Bruijn I, Gao J, Gross BE, Heins ZJ, Kundra R, La K, Ladanyi M, Luna A, Nissan MG, Ochoa A, Phillips SM, Reznik E, Sanchez-Vega F, Sander C, Schultz N, Sheridan R, Sumer SO, Sun Y, Taylor BS, Wang J, Zhang H, Anur P, Peto M, Spellman P, Benz C, Stuart JM, Wong CK, Yau C, Hayes DN, Parker JS, Wilkerson MD, Ally A, Balasundaram M, Bowlby R, Brooks D, Carlsen R, Chuah E, Dhalla N, Holt R, Jones SJM, Kasaian K, Lee D, Ma Y, Marra MA, Mayo M, Moore RA, Mungall AJ, Mungall K, Robertson AG, Sadeghi S, Schein JE, Sipahimalani P, Tam A, Thiessen N, Tse K, Wong T, Berger AC, Beroukhim R, Cherniack AD, Cibulskis C, Gabriel SB, Gao GF, Ha G, Meyerson M, Schumacher SE, Shih J, Kucherlapati MH, Kucherlapati RS, Baylin S, Cope L, Danilova L, Bootwalla MS, Lai PH, Maglinte DT, Van Den Berg DJ, Weisenberger DJ, Auman JT, Balu S, Bodenheimer T, Fan C, Hoadley KA, Hoyle AP, Jefferys SR, Jones CD, Meng S, Mieczkowski PA, Mose LE, Perou AH, Perou CM, Roach J, Shi Y, Simons JV, Skelly T, Soloway MG, Tan D, Veluvolu U, Fan H, Hinoue T, Laird PW, Shen H, Zhou W, Bellair M, Chang K, Covington K, Creighton CJ, Dinh H, Doddapaneni H, Donehower LA, Drummond J, Gibbs RA, Glenn R, Hale W, Han Y, Hu J, Korchina V, Lee S, Lewis L, Li W, Liu X, Morgan M, Morton D, Muzny D, Santibanez J, Sheth M, Shinbrot E, Wang L, Wang M, Wheeler DA, Xi L, Zhao F, Hess J, Appelbaum EL, Bailey M, Cordes MG, Ding L, Fronick CC, Fulton LA, Fulton RS, Kandoth C, Mardis ER, McLellan MD, Miller CA,

600

601

602

603

604 Schmidt HK, Wilson RK, Crain D, Curley E, Gardner J, Lau K, Mallery D, Morris S, Paulauskis J, Penny R, Shelton C, Shelton T, Sherman M, Thompson E, Yena P, Bowen J, Gastier-Foster JM, Gerken M, Leraas KM, Lichtenberg TM, Ramirez NC, Wise L, Zmuda E, Corcoran N, Costello T, Hovens C, Carvalho AL, de Carvalho AC, Fregnani JH, Longatto-Filho A, Reis RM, Scapulatempo-Neto C, Silveira HCS, Vidal DO, Burnette A, Eschbacher J, Hermes B, Noss A, Singh R, Anderson ML, Castro PD, Ittmann M, Huntsman D, Kohl B, Le X, Thorp R, Andry C, Duffy ER, Lyadov V, Paklina O, Setdikova G, Shabunin A, Tavobilov M, McPherson C, Warnick R, Berkowitz R, Cramer D, Feltmate C, Horowitz N, Kibel A, Muto M, Raut CP, Malykh A, Barnholtz-Sloan JS, Barrett W, Devine K, Fulop J, Ostrom QT, Shimmel K, Wolinsky Y, Sloan AE, De Rose A, Giuliante F, Goodman M, Karlan BY, Hagedorn CH, Eckman J, Harr J, Myers J, Tucker K, Zach LA, Deyarmin B, Hu H, Kvecher L, Larson C, Mural RJ, Somiari S, Vicha A, Zelinka T, Bennett J, Iacocca M, Rabeno B, Swanson P, Latour M, Lacombe L, Têtu B, Bergeron A, McGraw M, Staugaitis SM, Chabot J, Hibshoosh H, Sepulveda A, Su T, Wang T, Potapova O, Voronina O, Desjardins L, Mariani O, Roman-Roman S, Sastre X, Stern M-H, Cheng F, 
612 Signoretti S, Berchuck A, Bigner D, Lipp E, Marks J, McCall S, McLendon R, Secord A, Sharp A,

613 Behera M, Brat DJ, Chen A, Delman K, Force S, Khuri F, Magliocca K, Maithel S, Olson JJ, Owonikoko

614 T, Pickens A, Ramalingam S, Shin DM, Sica G, Van Meir EG, Zhang H, Eijckenboom W, Gillis A,

615 Korpershoek E, Looijenga L, Oosterhuis W, Stoop H, van Kessel KE, Zwarthoff EC, Calatozzolo C,

616 Cuppini L, Cuzzubbo S, DiMeco F, Finocchiaro G, Mattei L, Perin A, Pollo B, Chen C, Houck J,

617 Lohavanichbutr P, Hartmann A, Stoehr C, Stoehr R, Taubert H, Wach S, Wullich B, Kycler W, Murawa

618 D, Wiznerowicz M, Chung K, Edenfield WJ, Martin J, Baudin E, Bubley G, Bueno R, De Rienzo A,

619 Richards WG, Kalkanis S, Mikkelsen T, Noushmehr H, Scarpace L, Girard N, Aymerich M, Campo E,

620 Giné E, Guillermo AL, Van Bang N, Hanh PT, Phu BD, Tang Y, Colman H, Evason K, Dottino PR,

621 Martignetti JA, Gabra H, Juhl H, Akeredolu T, Stepa S, Hoon D, Ahn K, Kang KJ, Beuschlein F, Breggia

622 A, Birrer M, Bell D, Borad M, Bryce AH, Castle E, Chandan V, Cheville J, Copland JA, Farnell M, Flotte

623 T, Giama N, Ho T, Kendrick M, Kocher J-P, Kopp K, Moser C, Nagorney D, O’Brien D, O’Neill BP,

624 Patel T, Petersen G, Que F, Rivera M, Roberts L, Smallridge R, Smyrk T, Stanton M, Thompson RH,

625 Torbenson M, Yang JD, Zhang L, Brimo F, Ajani JA, Gonzalez AMA, Behrens C, Bondaruk J, Broaddus

626 R, Czerniak B, Esmaeli B, Fujimoto J, Gershenwald J, Guo C, Lazar AJ, Logothetis C, Meric-Bernstam

627 F, Moran C, Ramondetta L, Rice D, Sood A, Tamboli P, Thompson T, Troncoso P, Tsao A, Wistuba I,

628 Carter C, Haydu L, Hersey P, Jakrot V, Kakavand H, Kefford R, Lee K, Long G, Mann G, Quinn M, Saw

629 R, Scolyer R, Shannon K, Spillane A, Stretch J, Synott M, Thompson J, Wilmott J, Al-Ahmadie H, Chan

630 TA, Ghossein R, Gopalan A, Levine DA, Reuter V, Singer S, Singh B, Tien NV, Broudy T, Mirsaidi C,

631 Nair P, Drwiega P, Miller J, Smith J, Zaren H, Park J-W, Hung NP, Kebebew E, Linehan WM, Metwalli

632 AR, Pacak K, Pinto PA, Schiffman M, Schmidt LS, Vocke CD, Wentzensen N, Worrell R, Yang H,

633 Moncrieff M, Goparaju C, Melamed J, Pass H, Botnariuc N, Caraman I, Cernat M, Chemencedji I, Clipca

634 A, Doruc S, Gorincioi G, Mura S, Pirtac M, Stancul I, Tcaciuc D, Albert M, Alexopoulou I, Arnaout A,

635 Bartlett J, Engel J, Gilbert S, Parfitt J, Sekhon H, Thomas G, Rassl DM, Rintoul RC, Bifulco C,

636 Tamakawa R, Urba W, Hayward N, Timmers H, Antenucci A, Facciolo F, Grazi G, Marino M, Merola R,

637 de Krijger R, Gimenez-Roqueplo A-P, Piché A, Chevalier S, McKercher G, Birsoy K, Barnett G, Brewer

638 C, Farver C, Naska T, Pennell NA, Raymond D, Schilero C, Smolenski K, Williams F, Morrison C,

639 Borgia JA, Liptay MJ, Pool M, Seder CW, Junker K, Omberg L, Dinkin M, Manikhas G, Alvaro D,

640 Bragazzi MC, Cardinale V, Carpino G, Gaudio E, Chesla D, Cottingham S, Dubina M, Moiseenko F,

641 Dhanasekaran R, Becker K-F, Janssen K-P, Slotta-Huspenina J, Abdel-Rahman MH, Aziz D, Bell S,

642 Cebulla CM, Davis A, Duell R, Elder JB, Hilty J, Kumar B, Lang J, Lehman NL, Mandt R, Nguyen P,

643 Pilarski R, Rai K, Schoenfield L, Senecal K, Wakely P, Hansen P, Lechan R, Powers J, Tischler A,

644 Grizzle WE, Sexton KC, Kastl A, Henderson J, Porten S, Waldmann J, Fassnacht M, Asa SL,

645 Schadendorf D, Couce M, Graefen M, Huland H, Sauter G, Schlomm T, Simon R, Tennstedt P, Olabode

646 O, Nelson M, Bathe O, Carroll PR, Chan JM, Disaia P, Glenn P, Kelley RK, Landen CN, Phillips J,

647 Prados M, Simko J, Smith-McCune K, VandenBerg S, Roggin K, Fehrenbach A, Kendler A, Sifri S,

648 Steele R, Jimeno A, Carey F, Forgie I, Mannelli M, Carney M, Hernandez B, Campos B, Herold-Mende

649 C, Jungk C, Unterberg A, von Deimling A, Bossler A, Galbraith J, Jacobus L, Knudson M, Knutson T,

650 Ma D, Milhem M, Sigmund R, Godwin AK, Madan R, Rosenthal HG, Adebamowo C, Adebamowo SN,

651 Boussioutas A, Beer D, Giordano T, Mes-Masson A-M, Saad F, Bocklage T, Landrum L, Mannel R,

652 Moore K, Moxley K, Postier R, Walker J, Zuna R, Feldman M, Valdivieso F, Dhir R, Luketich J, Pinero

653 EMM, Quintero-Aguilo M, Carlotti CG, Dos Santos JS, Kemp R, Sankarankuty A, Tirapelli D, Catto J,

654 Agnew K, Swisher E, Creaney J, Robinson B, Shelley CS, Godwin EM, Kendall S, Shipman C, Bradford

655 C, Carey T, Haddad A, Moyer J, Peterson L, Prince M, Rozek L, Wolf G, Bowman R, Fong KM, Yang I,

Peer] reviewing PDF | (2020:09:53301:1:2:NEW 16 Dec 2020) 
656 Korst R, Rathmell WK, Fantacone-Campbell JL, Hooke JA, Kovatich AJ, Shriver CD, DiPersio J, Drake 657 B, Govindan R, Heath S, Ley T, Van Tine B, Westervelt P, Rubin MA, Lee JI, Aredes ND, Mariamidze 658 A. 2018. Comprehensive Molecular Characterization of the Hippo Signaling Pathway in Cancer. Cell 659 Reports 25:1304-1317.e5. DOI: 10.1016/j.celrep.2018.10.001.

660 Westfall TA, Brimeyer R, Twedt J, Gladon J, Olberding A, Furutani-Seiki M, Slusarski DC. 2003. Wnt$6615 /$ pipetail functions in vertebrate axis formation as a negative regulator of Wnt/ $\beta$-catenin activity. Journal 662 of Cell Biology 162:889-898. DOI: 10.1083/jcb.200303107.

663 Young JC, Kerr G, Micati D, Nielsen JE, Rajpert-De Meyts E, Abud HE, Loveland KL. 2020. WNT 664 signalling in the normal human adult testis and in male germ cell neoplasms. Human Reproduction 665 35:1991-2003. DOI: 10.1093/humrep/deaa150.

666 Zanconato F, Cordenonsi M, Piccolo S. 2016. YAP/TAZ at the Roots of Cancer. Cancer Cell 29:783667803.

668 Zanconato F, Forcato M, Battilana G, Azzolin L, Quaranta E, Bodega B, Rosato A, Bicciato S, 669 Cordenonsi M, Piccolo S. 2015. Genome-wide association between YAP/TAZ/TEAD and AP-1 at 670 enhancers drives oncogenic growth. Nature Cell Biology 17:1218-1227. DOI: 10.1038/ncb3216.

671 Zhao B, Ye X, Yu J, Li L, Li W, Li S, Yu J, Lin JD, Wang C-Y, Chinnaiyan AM, Lai Z-C, Guan K-L. 672 2008. TEAD mediates YAP-dependent gene induction and growth control. Genes \& Development 673 22:1962-1971. DOI: 10.1101/gad.1664408.

674 Zheng Y, Pan D. 2019. The Hippo Signaling Pathway in Development and Disease. Developmental Cell 675 50:264-282. DOI: 10.1016/j.devcel.2019.06.003.

676 Zheng R, Wan C, Mei S, Qin Q, Wu Q, Sun H, Chen C-H, Brown M, Zhang X, Meyer CA, Liu XS. 2019. 677 Cistrome Data Browser: expanded datasets and new tools for gene regulatory analysis. Nucleic Acids 678 Research 47:D729-D735. DOI: 10.1093/nar/gky1094.

679 


\section{Figure 1}

Figure 1. Binding sites with high regulatory potential scores for WNT5A, LATS2, and YAP1.

Data was obtained using CistromeDB, spanning a region of $\sim 10 \mathrm{~kb}$ upstream the transcription start site (TSS) of theWNT5A (A), LATS2 (B), and YAP1 (C) genes. YAP/TEAD proteins are highlighted in bold. 

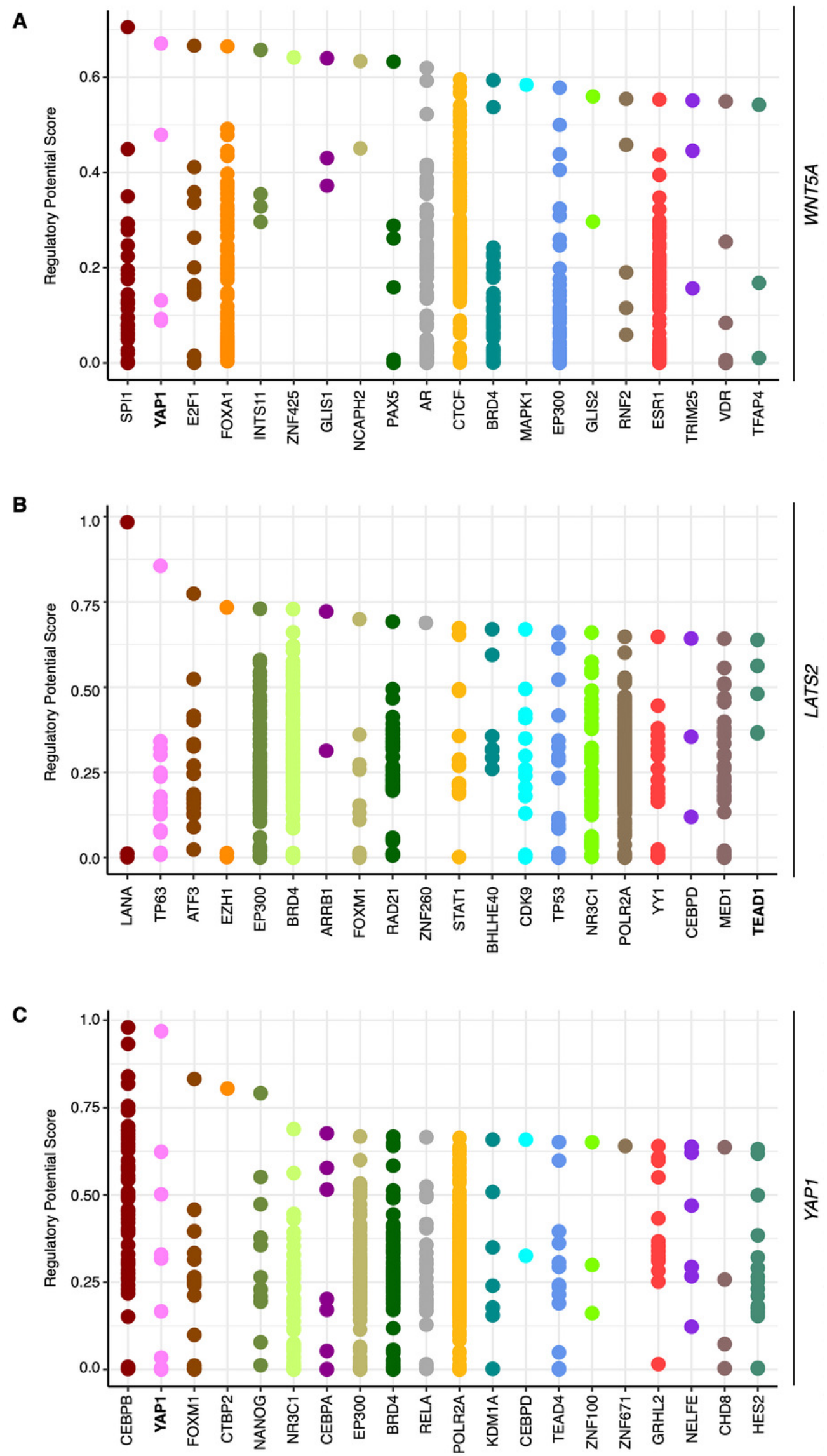


\section{Figure 2}

Figure 2. YAP/TEAD binding sites upstream the WNT5A transcription start site (TSS).

(A) ChIP-Seq data mapped onto a region spanning $\sim 10 \mathrm{~kb}$ upstream of the transcription start site (TSS) of the WNT5Agene, using the IGV browser. The data for each co-factor (YAP1), transcription factors (TEAD1, TEAD4, JUN, FOS), and histone modifications (H3K27ac, H3K4me1, and H3K4me3), correspond to separate experiments, represented by different colors. See the main text for details. (B) Evolutionary conserved regions (ECRs) between the human, mouse, and rat Wnt5a gene. The same region shown in (A) was analyzed using the ECR Browser. The dashed box shows the matching region enriched for YAP/TEAD binding, according to ChIP-Seq data. (C) Data from the specified KnockTF dataset showing WNT5A (in bold) as a downregulated gene after TEAD4 knockdown.

A

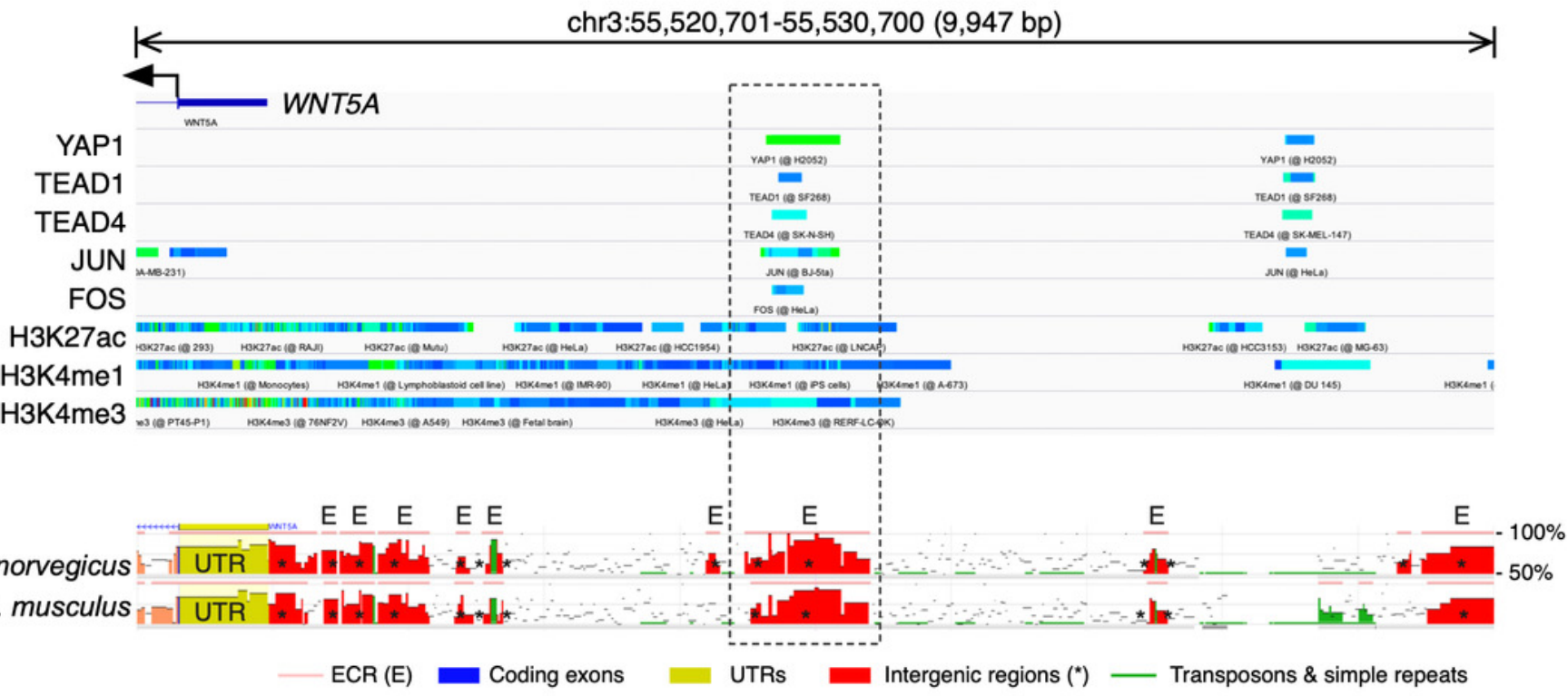

C

KnockTF database (Dataset_01_151)

Top 10 down- and up-regulated after TEAD4 shRNA (SNU216 cell line)

\begin{tabular}{|r|c|c|c|c|c|c|c|c|c|c|}
\hline Target Gene & TNNC1 & PSG5 & WNT5A & IGFBP5 & PSG9 & CLIC3 & TAGLN & SERPINB7 & EDN2 & TEAD4 \\
\hline Log2FC & -2.36977 & -2.35015 & -2.18729 & -2.01602 & -1.83235 & -1.80408 & -1.8035 & -1.78411 & -1.70057 & -1.66583 \\
\hline
\end{tabular}

\begin{tabular}{|r|c|c|c|c|c|c|c|c|c|c|}
\hline Target Gene & CXCL1 & IL8 & ATF5 & SPOCD1 & PRSS22 & EPHA2 & GNG11 & STMN3 & BASP1 & FSCN1 \\
\hline Log2FC & 1.57164 & 1.59299 & 1.61683 & 1.66999 & 1.91887 & 1.98364 & 2.06681 & 2.10062 & 2.18158 & 2.44012 \\
\hline
\end{tabular}




\section{Figure 3}

Figure 3. Correlation between WNT5A and YAP1 expression across cancer types.

(A) Heat map (Spearman correlation coefficients) retrieved from TIMER, showing the correlation between WNT5A and YAP1 expression across the indicated cancer types (ACC, Adrenocortical carcinoma; BLCA, Bladder Urothelial Carcinoma; BRCA, Breast invasive carcinoma; CESC, Cervical squamous cell carcinoma and endocervical adenocarcinoma; CHOL, Cholangiocarcinoma; COAD, Colon adenocarcinoma; DLBC, Lymphoid Neoplasm Diffuse Large B-cell Lymphoma; ESCA, Esophageal carcinoma; GBM, Glioblastoma multiforme; HNSC, Head and Neck squamous cell carcinoma; KICH, Kidney Chromophobe; KIRC, Kidney renal clear cell carcinoma; KIRP, Kidney renal papillary cell carcinoma; LGG, Brain Lower Grade Glioma; LIHC, Liver hepatocellular carcinoma; LUAD, Lung adenocarcinoma; LUSC, Lung squamous cell carcinoma; MESO, Mesothelioma; OV, Ovarian serous cystadenocarcinoma; PAAD, Pancreatic adenocarcinoma; PCPG, Pheochromocytoma and Paraganglioma; PRAD, Prostate adenocarcinoma; READ, Rectum adenocarcinoma; SARC, Sarcoma; SKCM, Skin Cutaneous Melanoma; STAD, Stomach adenocarcinoma; TGCT, Testicular Germ Cell Tumors; THCA, Thyroid carcinoma; THYM, Thymoma; UCEC, Uterine Corpus Endometrial Carcinoma; UCS, Uterine Carcinosarcoma; UVM, Uveal Melanoma). (B-G) Correlation between WNT5A and YAP1 expression in the indicated cancer types, according to data from GEPIA, using tumor (top; B-D) and GTEx normal (bottom; E-G) data. Spearman correlation coefficients were automatically computed and are shown at the top of each plot. TPM, transcript per million. 

A
Partial_Cor $\quad \begin{aligned} & 1 \\ & 0\end{aligned}$
$\bigotimes p>0.05$
$-1$
口 $\mathrm{p} \ldots .0 .05$

YAP1

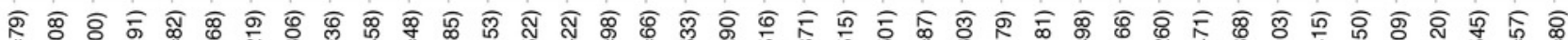

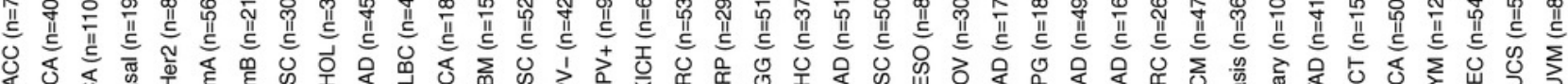

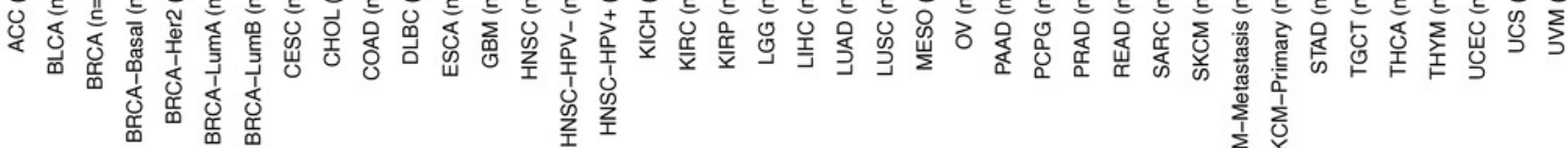

B

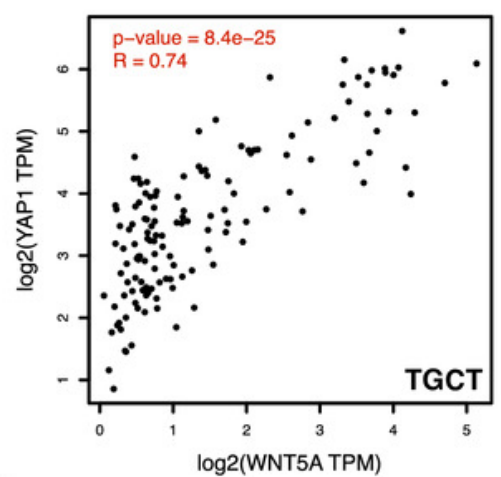

E

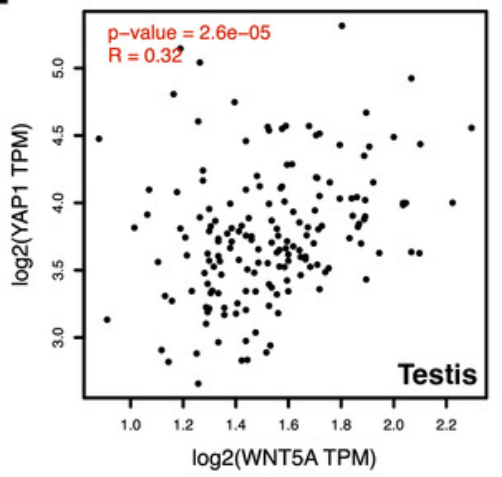

C

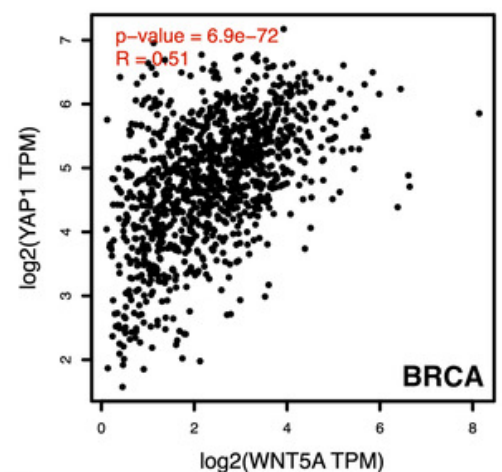

F

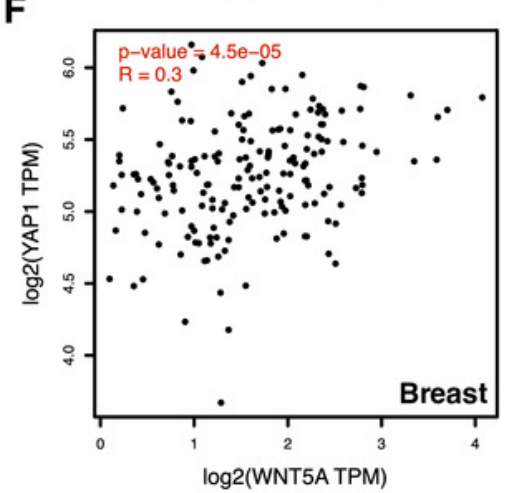

D

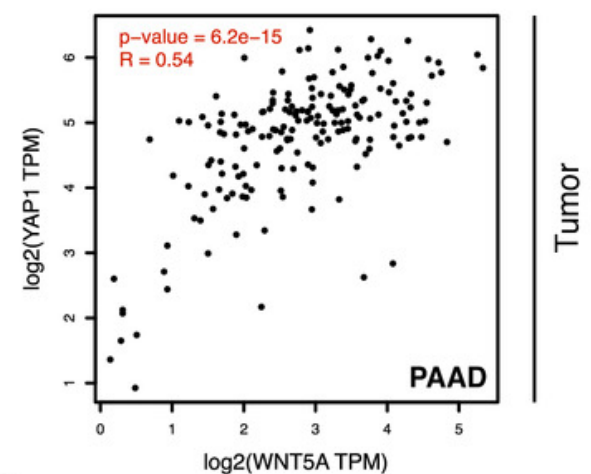

G

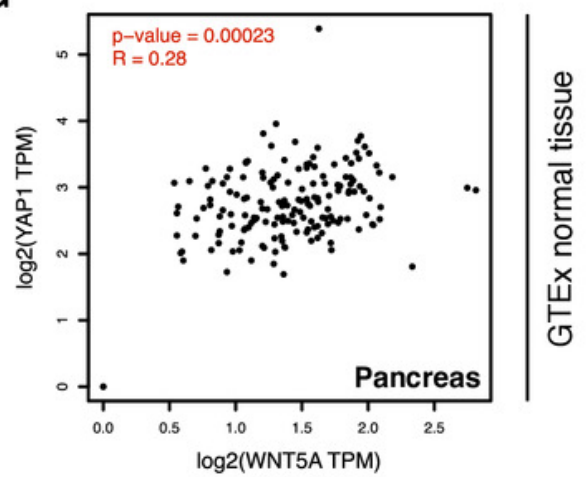


Figure 4

Figure 4. Correlation between WNT5A expression and a YAP/TEAD gene signature.

Tumor (top) and the corresponding GTEx normal tissue (bottom) data are shown for the indicated cancer types, and the correlation between WNT5A and the 'YAP/TEAD' signature (CTGF plus ANKRD1) was estimated using the 'Gene Signature' option in GEPIA. Spearman correlation coefficients were automatically computed and are shown at the top of each plot.
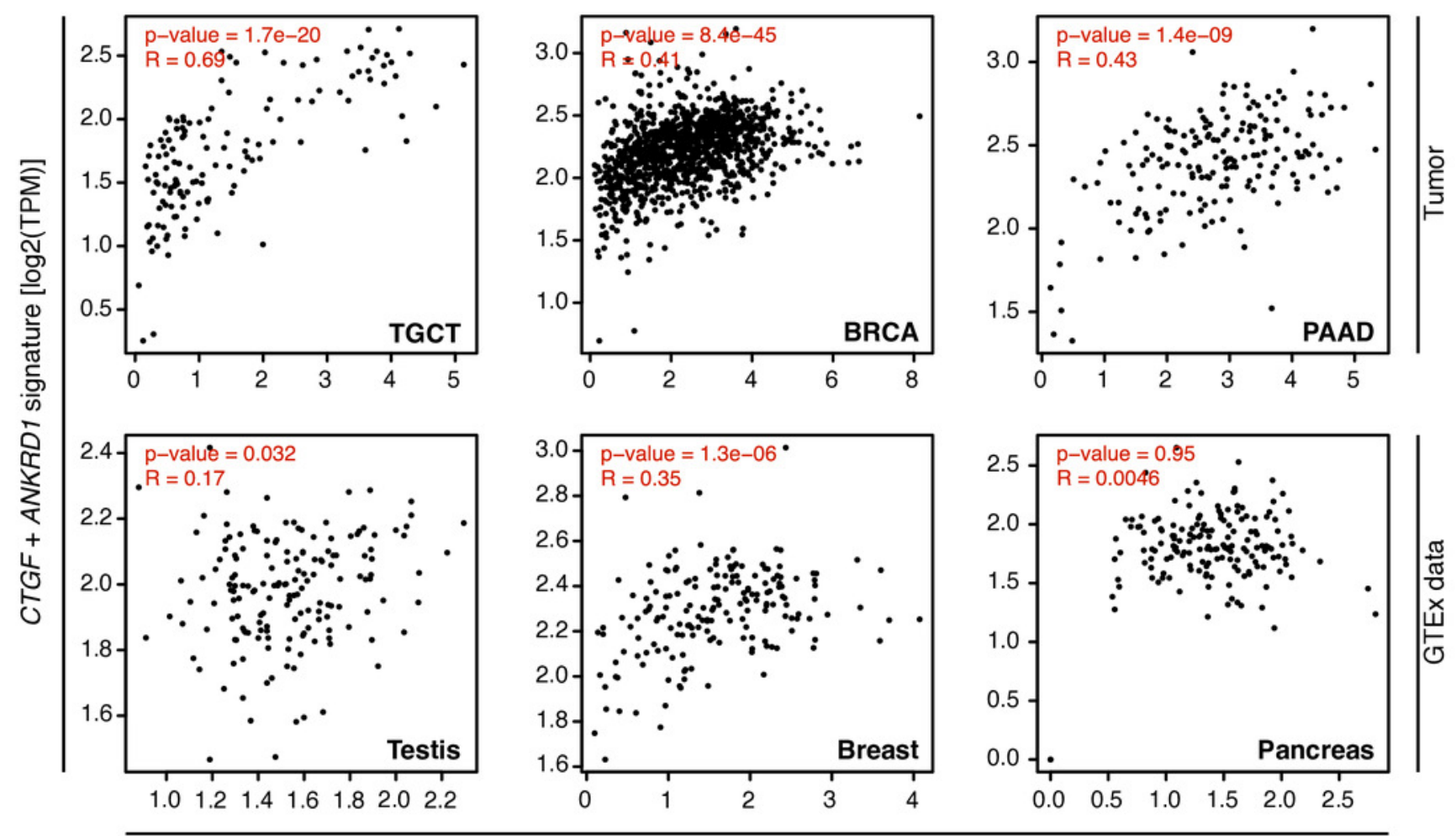

WNT5A [log2(TPM)] 
Figure 5

Figure 5. Correlation between WNT5A and YAP protein expression and JNK/AKT phosphorylation in Testicular Germ Cell Tumors.

(A) Correlation between WNT5A and YAP protein expression in TGCT cancer. The data was retrieved from cBioPortal (see 'Methods' for the parameters used for the analysis).

Correlation between YAP protein expression and JNK (left) and AKT (right) protein phosphorylation, according to The Cancer Proteome Atlas.

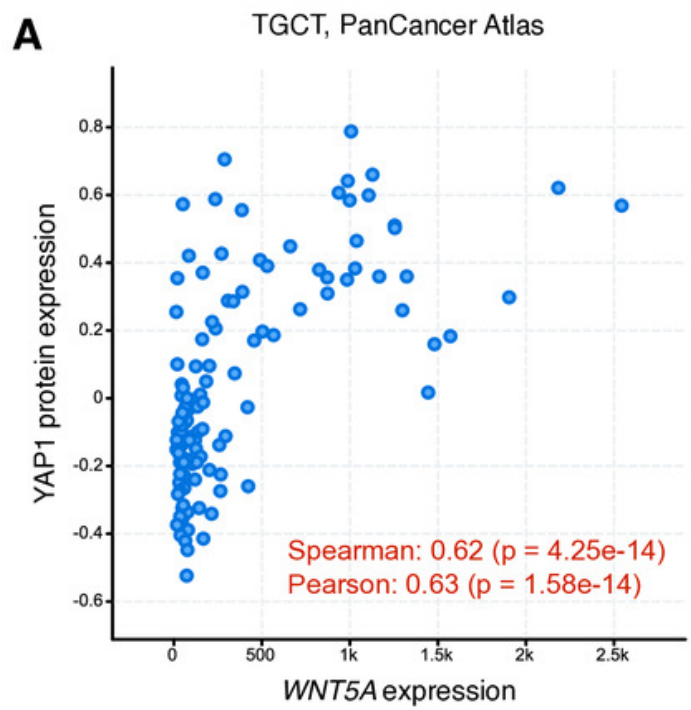

B

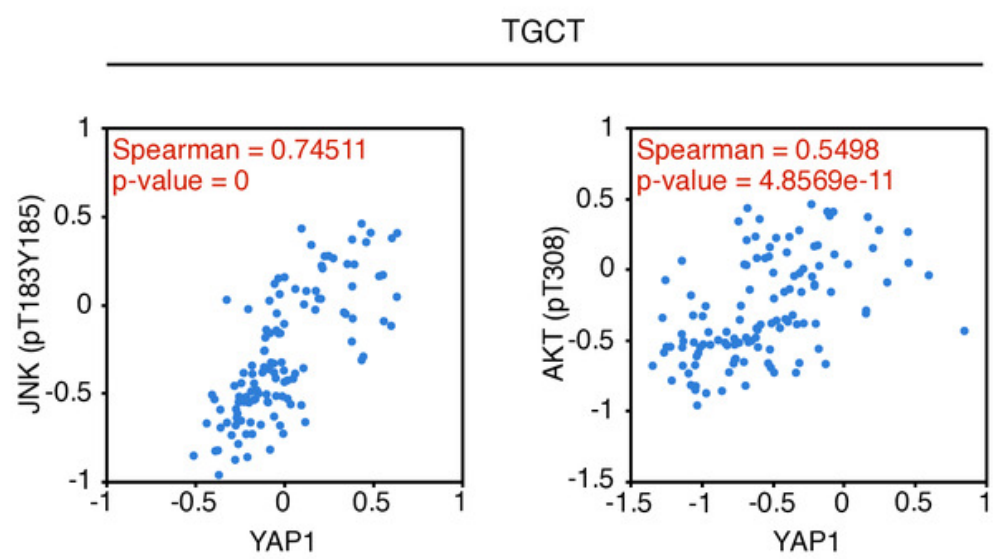

